\title{
Physicochemical Properties of Various Shellac Types
}

\author{
Y. Farag and C. S. Leopold ${ }^{1}$ \\ University of Hamburg, Institute of Pharmacy, Department of Pharmaceutical Technology, \\ Bundesstrasse 45, 20146 Hamburg, Germany
}

e-mail:Claudia.Leopold@uni-hamburg.de

\begin{abstract}
Shellac in its acid form undergoes aging, resulting in the change of its physicochemical properties. Therefore, various shellac types were investigated as free films prepared from ammoniacal solutions and as micronized powder in its acid form. Due to its acidic character, shellac shows a pH-dependent solubility. The dissolution properties of shellac films prepared from ammoniacal solution were investigated at various $\mathrm{pH}$ values using a dissolution apparatus with basket holder. Micronized shellac in its acid form was analyzed using the intrinsic dissolution method (Ph. Eur.) with a paddleover-disk apparatus. The dissolution properties of the investigated shellac types were correlated with their acid values and their thermal properties. Aging of shellac results in an increase in the glass transition temperature and a decrease in the acid value and the solubility. However, the extent of this change in physicochemical properties depends on the type of shellac, its origin, and type of refining process. Besides the acid value and the glass transition temperature, the intrinsic dissolution rate is an important parameter for the characterization of different shellac types.
\end{abstract}

\section{INTRODUCTION}

S hellac is the purified product of lac, a natural resinous oligomer ( $\mathrm{MW} \approx 1000 \mathrm{D}$ ) secreted by the parasitic insect Kerria lacca on various host trees in India, Thailand, and Myanmar. Shellac consists of polyesters of mainly aleuritic acid, shellolic acid, and a small amount of free aliphatic acids $(1,2)$. The composition varies depending on the insect species as well as the host tree from which the raw material is obtained.

After harvesting, the so-called "stick lac" is chopped and separated from wood and resin. A washing step extracts the water-soluble dye, laccaic acid, yielding the raw material "seed lac." There are three different processes used for refining, resulting in different shellac qualities: The melting filtration process, where melted seed lac is filtered through a cotton hose, leads to wax containing shellac. Bleached shellac is obtained by treating the dissolved polymer with sodium hypochlorite. The most suitable type of refining is the solvent-extraction process, in which the raw material is dissolved in alcohol, decolorized by treatment with activated carbon, filtered, and cast to a film. After cooling, the film breaks into flakes giving shellac its typical appearance (3). The solvent-extraction process is a gentle process that does not change the chemical structure of the material. Careful selection of the raw material ensures shellac qualities with narrow specifications.

Due to its acidic character, shellac is used primarily as an enteric coating. Other applications are sustained release (4), colon targeting (5), and microencapsulation (6). Shellac is non-toxic and physiologically harmless (7); it is therefore listed as GRAS by the FDA.This makes shellac suitable for

${ }^{1}$ Corresponding author. use even in foods or confectionaries. Shellac has excellent film-forming properties, high gloss, and poor permeability to gases and water vapor $(8,9)$.

Despite these advantages, the use of shellac as a pharmaceutical excipient has significantly declined, because historically, shellac was mainly used in alcoholic solutions. Shellac films prepared from alcoholic solutions show pronounced hardening induced by a continuing polymerization process. This results in a loss of gastric resistance and a decrease in intestinal fluid solubility, both leading to major changes in drug dissolution profiles. These are disadvantages when compared with synthetic or partially synthetic polymers such as polymethacrylates and cellulose derivatives.

Nevertheless, it could be shown that shellac films prepared from ammoniacal solutions lack these material changes during storage $(10,11)$. Thus, aqueous shellac solutions could regain importance in pharmaceutical applications.

Although shellac films prepared from aqueous solutions show better stability, the raw material is still prepared by solvent extraction, which results in the unstable acid form. Therefore, besides origin and type of refining process, further processing to an aqueous formulation has a major effect on the quality of the material.

In the present study, shellac batches of different ages and origins were investigated with regard to their dissolution properties at various $\mathrm{pH}$ values, and the dissolution rates were correlated to the acid values and thermal properties.

\section{MATERIALS AND METHODS Materials}

The shellac types are listed below. All other reagents were of analytical grade. 


\begin{tabular}{|c|c|c|c|}
\hline Shellac Type & Batch & $\begin{array}{c}\text { Manufacturing } \\
\text { Date }\end{array}$ & Manufacturer \\
\hline \multirow[t]{3}{*}{ SSB 55 Pharma } & 7174 & $07 / 2003$ & \multirow{7}{*}{$\begin{array}{l}\text { Syntapharm, } \\
\text { Mülheim an der } \\
\text { Ruhr, Germany }\end{array}$} \\
\hline & 109620 & $04 / 2007$ & \\
\hline & 110580 & $11 / 2007$ & \\
\hline SSB MB Bys-Ber & $2918 A$ & $04 / 2007$ & \\
\hline SSB MB Bys-Pal & 2918 B & $04 / 2007$ & \\
\hline SSB 56 Pharma & 7249 & $08 / 2003$ & \\
\hline SSB 57 Pharma & 7176 & $07 / 2003$ & \\
\hline Shellac 101 & 564 & $12 / 2005$ & $\begin{array}{l}\text { Renschel, Bremen } \\
\text { Germany }\end{array}$ \\
\hline Platina Shellac & SSF-134-2004-05 & $09 / 2005$ & $\begin{array}{l}\text { Shraddha Seedlac } \\
\text { Factory, Kolkata, } \\
\text { India }\end{array}$ \\
\hline
\end{tabular}

\section{Methods}

Preparation of the Raw Material

Ground shellac was prepared by milling shellac flakes in a Waring Blender fly cutter and sieving through a 400- $\mu \mathrm{m}$ mesh sieve. Ground shellac was used for the preparation of shellac solutions and for the determination of acid values and glass transition temperatures $\left(T_{g}\right)$.

To achieve better compaction properties for intrinsic dissolution studies and to achieve a faster dissolution for the determination of the $\mathrm{p} K_{a}$ values, ground shellac was micronized using an Imperial Eastman air jet micronizer.

\section{Preparation of Aqueous Shellac Solutions}

Ground shellac was dissolved in 1\% ammonium bicarbonate solution at $50{ }^{\circ} \mathrm{C}$ to obtain a final concentration of $10 \%(\mathrm{~m} / \mathrm{V})$. As the presence of excessive ammonium salt influences the dissolution properties of shellac films, the solutions were heated to $65^{\circ} \mathrm{C}$ to remove the excess ammonium salt by evaporation of free ammonia. Evaporated water was replaced. This process was repeated until a constant $\mathrm{pH}$ was reached. The $\mathrm{pH}$ of the final solutions was between 7.3 and 7.9 (Mettler Toledo MP $225 \mathrm{pH}$ meter).

\section{Acid Values}

The acid value (AV) was determined by an acid-base titration method adapted from the European Pharmacopoeia (Ph. Eur.). Briefly, $0.4 \mathrm{~g}$ of ground shellac was dissolved in a mixture of diethyl ether and ethanol (1:1) and titrated with $0.1 \mathrm{M}$ potassium hydroxide solution. Because of the dark color of the shellac solutions, instead of using a color indicator, the endpoint was determined potentiometrically (Mettler Toledo DL70ES Titrator). The AV is expressed as milligram of potassium hydroxide per gram of shellac. The average of five measurements was determined.

\section{Preparation of Free Shellac Films}

Films were prepared by a casting-and-evaporation method in which $20 \mathrm{~mL}$ of the shellac solutions was poured onto $10 \times 10 \mathrm{~cm}$ Teflon plates. Solvent evaporation was carried out at $50^{\circ} \mathrm{C}$ for $4-5$ hours. After complete drying, the films were carefully peeled off the plates and cut into $2 \times 2 \mathrm{~cm}$ samples for dissolution testing using a sharp square-formed punch. The thickness of the shellac films was determined to be 80-190 $\mu \mathrm{m}$, measured at three spots per film using a Mitutoyo Digimatic Indicator. For thermal analysis, circles with a diameter of $6 \mathrm{~mm}$ were prepared using a circular punch. The film samples were stored in a desiccator at room temperature over silica gel until use.

\section{Glass Transition Temperatures}

Shellac films cast from aqueous solutions and ground shellac in acid form were investigated using DSC (Perkin Elmer, DSC 7, TAC 7/DX, liquid nitrogen cooling system). About $10 \mathrm{mg}$ of film or powder was accurately weighed into a standard aluminum pan with a punctured cap and measured twice under nitrogen atmosphere over a temperature range of -40 to $120^{\circ} \mathrm{C}$. Between the heating runs at $20 \mathrm{~K} / \mathrm{min}$, an isothermal step of $1 \mathrm{~min}$ at $120^{\circ} \mathrm{C}$ was introduced to remove excessive water. The $T_{g}$ was determined from the second heating run by the Perkin Elmer Pyris software.

\section{Dissolution Profiles of Free Films}

Phosphate buffers of different $\mathrm{pH}$ values $(\mathrm{pH} 7.0,7.2,7.4$, 8.0) were prepared according to the method described in Ph. Eur. 2.9.3. The required amount of $0.2 \mathrm{M}$ sodium hydroxide solution was added to $250 \mathrm{~mL}$ of $0.2 \mathrm{M}$ potassium dihydrogen phosphate solution. The $\mathrm{pH}$ value was measured using the Mettler Toledo $\mathrm{pH}$ meter. The $2 \times 2 \mathrm{~cm}$ shellac films were accurately weighed and placed in the basket holder of a Sotax Premiere 5100 dissolution apparatus. Dissolution was performed at $37^{\circ} \mathrm{C}$ and $150 \mathrm{rpm}$. The dissolution profiles were recorded spectrophotometrically at $223 \mathrm{~nm}$ in triplicate every two minutes using a Kontron Uvicon 930 spectrophotometer and 1-cm flow-through cells at a flow rate of about $15 \mathrm{~mL} / \mathrm{min}$ for $150 \mathrm{~min}$.

\section{Intrinsic Dissolution}

Intrinsic dissolution profiles were recorded using a Distek paddle-over-disk intrinsic dissolution kit. Eighty milligrams of micronized shellac was weighed into a 9-mm die and compressed for two minutes at a compression force of $200 \mathrm{~kg}$. The resulting sample discs were placed into the intrinsic dissolution vessels prefilled with $1000 \mathrm{~mL}$ of phosphate buffer (see above).

Dissolution was performed at $37^{\circ} \mathrm{C}$ and $100 \mathrm{rpm}$. The dissolution profiles were recorded spectrophotometrically at $223 \mathrm{~nm}$ in triplicate every two minutes using a Perkin Elmer Lambda 25 spectrophotometer and 1-cm flowthrough cells at a flow rate of about $20 \mathrm{~mL} / \mathrm{min}$ for $90 \mathrm{~min}$. 
The intrinsic dissolution rate was determined from the slope of the dissolution profile and expressed as $\mathrm{mg}$ shellac dissolved per $\mathrm{cm}^{2}$ and $\mathrm{min}$.

\section{$\mathrm{p} K_{a}$ Values}

For determination of the $\mathrm{p} K_{a}$ values, acid-base back titrations were performed based on a method adapted from Parke and Davis (12). Briefly, $0.2 \mathrm{~g}$ of accurately weighed micronized shellac was dissolved in $8.0 \mathrm{~mL}$ of $0.1 \mathrm{M}$ sodium hydroxide solution. Hydrolysis induced by the alkali treatment was observed, manifesting itself as a darkening of the solutions. As described in the literature (13), the effect of the hydrolysis on the $\mathrm{p} K_{a}$ values was nonsignificant. Nonetheless, the samples were titrated immediately after complete dissolution, and dissolution time periods were kept the same for all samples of a batch. Dissolution time periods for SSB 55 Pharma, SSB Bys Pal, and SSB Bys Ber were about 20 min, and for the older batches about one hour. Titrations were done in $50-\mu \mathrm{L}$ steps with $0.1 \mathrm{M}$ hydrochloric acid, and the titration profile was recorded potentiometrically. A blank curve was recorded by titration of $8.0 \mathrm{~mL}$ of $0.1 \mathrm{M}$ sodium hydroxide solution without shellac. The shellac titration curves were subtracted from the blank curve and standardized referring to the sample weight. The $\mathrm{p} K_{a}$ could be determined from the $\mathrm{pH}$ value at a titration grade of 0.5 . Eudragit $L$ and acetic acid served as reference substances.

\section{RESULTS AND DISCUSSION}

The acid value (AV) is a good indicator for the quality of the shellac raw material. During storage, polymerization induced by esterification takes place, resulting in a decrease in the AV.Therefore, the quality of the product can be estimated by comparison with the manufacturer's certificate of analysis.

The AV was measured for seven different shellac batches of five shellac types. Compared with the manufacturer's certificate of analysis, all measured AVs (Figure 1) were lower. The time-dependent decrease in the AV during

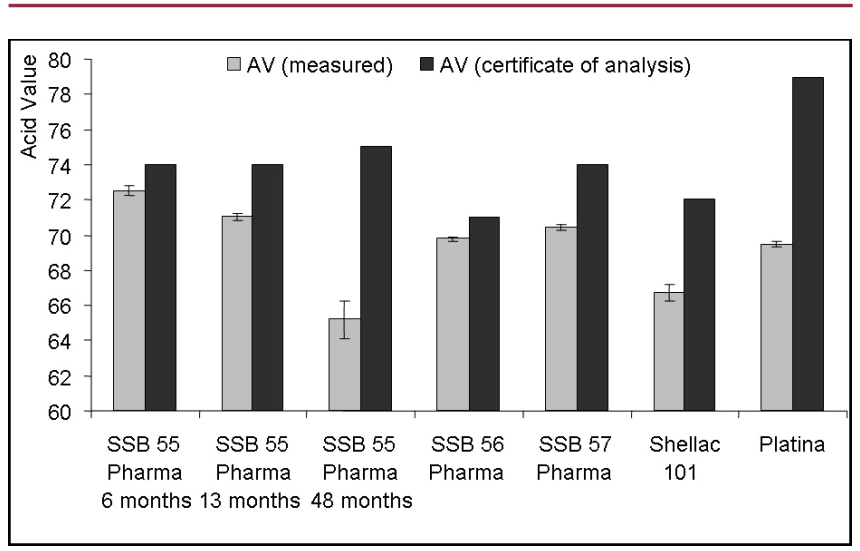

Figure 1. Acid values of the investigated shellac types (mean $\pm S D, n=5$ ). storage was most significant for the three batches of SSB 55 Pharma. Whereas the youngest batch 110580 (6 months) already showed a decrease of $1.5 \mathrm{AV}$ units, the decrease in the 13-month batch 109620 was three AV units. The five-year-old batch 7174, on the other hand, showed a very pronounced decrease of almost ten AV units. The effect of aging on the AV within one batch is still under investigation.

The structural change in the material also affects the dissolution behavior in the testing solvent during AV measurement. Whereas the two younger batches dissolved completely within almost $15 \mathrm{~min}$ in the ethanol-ether mixture, it took almost one hour for the oldest batch to dissolve. Interestingly, the rate of AV decrease varied with the investigated shellac type. For instance, the youngest batch of SSB 55 Pharma showed a decrease of 1.5 AV units during only half a year of storage, whereas the decrease for SSB 56 Pharma was the same for a storage period of more than four years. Another significant decrease of almost ten AV units was observed for Platina shellac. Interestingly, in contrast to the SSB 55 Pharma batch, this decrease was not accompanied by a change in the dissolution behavior in the testing solvent.

The decrease in AV can easily be explained by the age of most of the batches and polymerization during storage. However, the rate of AV decrease and the resulting change in the material properties are different for the investigated shellac types.

The decrease in AV correlates with an increase in the glass transition temperature $\left(T_{g}\right)$. As shown for the three batches of SSB 55 Pharma in Figure 2, the $T_{\mathrm{g}}$ and AV remain almost unchanged for the younger batches but change significantly with the older batch. During longterm storage, polymerization and thus ester formation takes place, resulting in the formation of additional bonding and therefore a tighter structure with higher $T_{g}$.

The $T_{g}$ values of the ground shellac in its acid form, shown in Figure 3 , vary from 37 to $49^{\circ} \mathrm{C}$. Again, the $T_{g}$

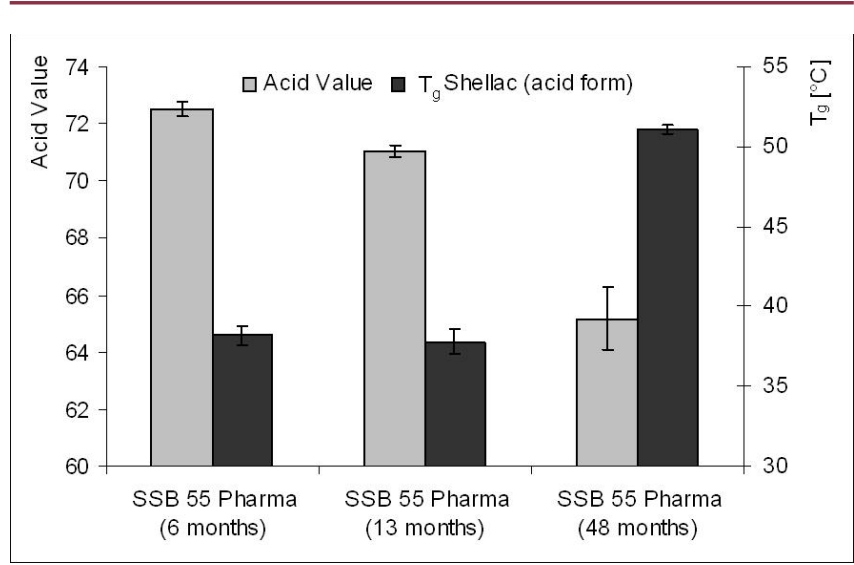

Figure 2. Correlation of acid values and glass transition temperatures for three batches of SSB 55 Pharma (mean $\pm S D, n=5[A V], n=3\left[T_{g}\right]$ ). 


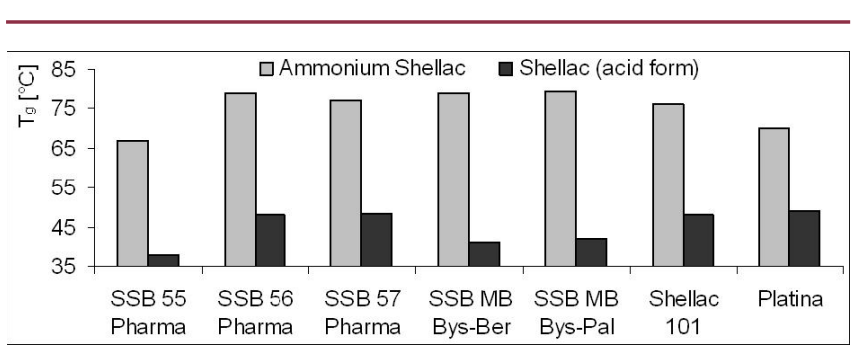

Figure 3. Glass transition temperatures of the investigated shellac types in acid and ammonium salt form (mean $\pm S D, n=3$ ).

values of the older batches are higher compared with the younger batches of SSB 55 Pharma, SSB MB Bys-Ber, and SSB MB Bys-Pal. In comparison, the $T_{g}$ values of the cast films are significantly elevated due to salt formation with ammonium ions. The increase in $T_{g}$ explains the brittleness of the unplasticized films prepared from aqueous solutions.

The aging of shellac results in a change in dissolution properties. Aged shellac shows a reduction in gastric resistance and a decreased solubility in intestinal fluids. This can have consequences for shellac-coated dosage forms. Due to the already poor water solubility of shellac and its comparatively high dissolution $\mathrm{pH}$ of about 7.3 (14), a further reduction in the solubility might lead to incomplete drug release. On the other hand, acid-labile drug substances could be degraded because of an increased permeability to gastric fluid caused by the loss of gastric resistance.

Various shellac films prepared from aqueous solutions were investigated with regard to their dissolution properties at various $\mathrm{pH}$ values. The basket holder was a suitable tool for the dissolution experiments. With the paddle stirring element, the shellac films either began to float or were attached to the sampling device of the dissolution apparatus. Particularly after longer dissolution periods, swollen shellac films were destroyed by shearing forces of the paddle.

As shown in Figure 4, shellac shows a UV maximum at $223 \mathrm{~nm}$ independent of the shellac type. The UV spectra of the investigated shellac types are almost superimposable. This indicates that the differences between shellac types are caused only by different amounts of the various ingredients and not by their nature. The absorption coefficient $A_{1 c m}^{1 \%}$ was determined to be 103-122 depending on the investigated batch. Because only the raw material without additives was investigated, spectrophotometric detection was a suitable method for recording the dissolution profiles.

Because shellac is a weak acid, the dissolution profiles were expected to be $\mathrm{pH}$-dependent. This $\mathrm{pH}$ dependence was confirmed for all samples. With increasing $\mathrm{pH}$ value, the dissolution rate and the amount of dissolved shellac increased.

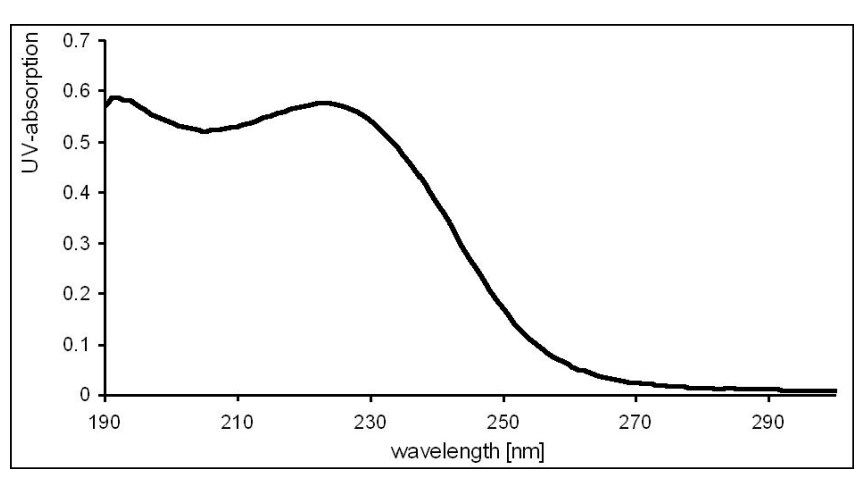

Figure 4. UV spectrum of a solution of Shellac SSB 57 Pharma $(50 \mu \mathrm{g} / \mathrm{mL})$.

The recorded dissolution profiles are shown in Figure 5. Except for shellac batches SSB 56 Pharma and SSB 57 Pharma (Figure 5A), which do not dissolve completely even at $\mathrm{pH} 8.0$, all samples of the investigated shellac batches showed complete dissolution at $\mathrm{pH}$ values above 7.4. The shellac type SSB 55 Pharma already dissolved completely at a $\mathrm{pH}$ value of 7.2. Only the dissolution rate of the various shellac types differed. Whereas the complete dissolution of SSB 55 Pharma took place in less than $30 \mathrm{~min}$ for all $\mathrm{pH}$ values above 7.2, the batches of SSB MB Bys Ber and SSB Bys Pal of the same age needed almost one hour for complete dissolution. With the batches of Shellac 101 and Platina Shellac, an interesting phenomenon was observed. Both batches showed a step in the dissolution profile at a dissolved amount of almost $20 \%$. At this step, a sudden increase in the dissolution rate occurred, and the films dissolved completely within $15 \mathrm{~min}$. This phenomenon can be explained by a pronounced swelling and breakup of the film structure. This water uptake was also observed for the undissolved films, which turned from translucent amber to off-white.

However, the dissolution behavior of the films does not correlate with the observed decrease in the AV values. As observed during determination of the AV, Platina shellac, which showed a significant AV decrease of 10 units, dissolved at $\mathrm{pH} 7.4$, whereas SSB 56 Pharma, showing only a slight AV decrease, did not dissolve completely even at $\mathrm{pH}$ 8.0. Although the AV decrease observed for SSB 55 Pharma amounted to 3 units, fast dissolution took place at $\mathrm{pH}$ 7.2. Obviously, the dissolution behavior does not depend only on the polymerization induced by esterification during storage.

Dissolution of the shellac films is an adequate method for characterization of the different shellac batches. However, from the sigmoid shape of the profiles, an overall parameter describing the dissolution properties can hardly be determined. In contrast, intrinsic dissolution (ID) provides such an option. Hereby, the investigated substance is compacted by a punch in a die to achieve minimum porosity. The die containing the sample disc is placed in the dissolution apparatus providing a constant 


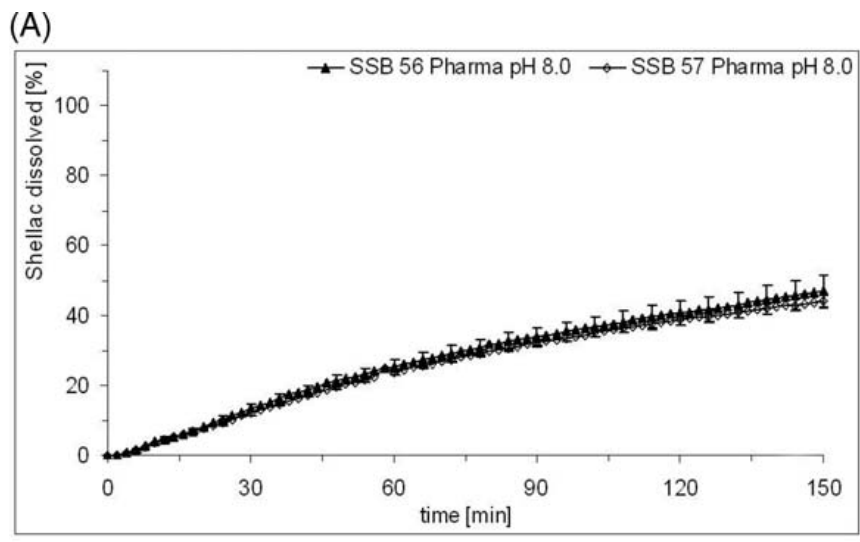

(D)

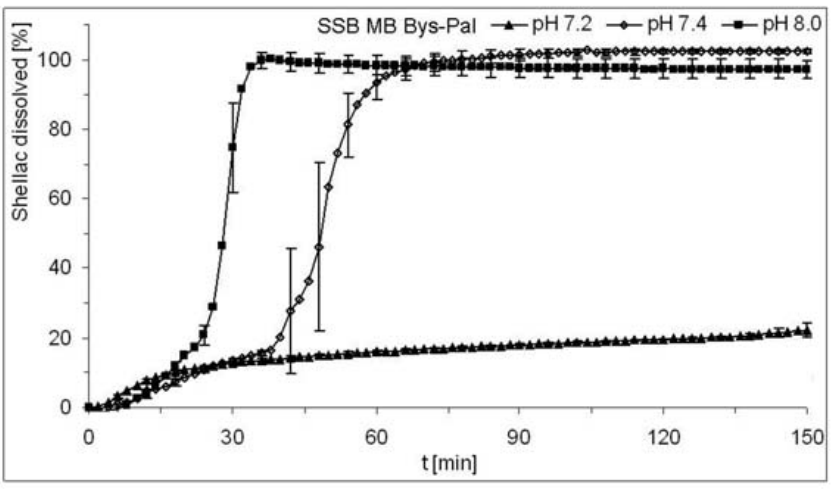

(B)

(E)
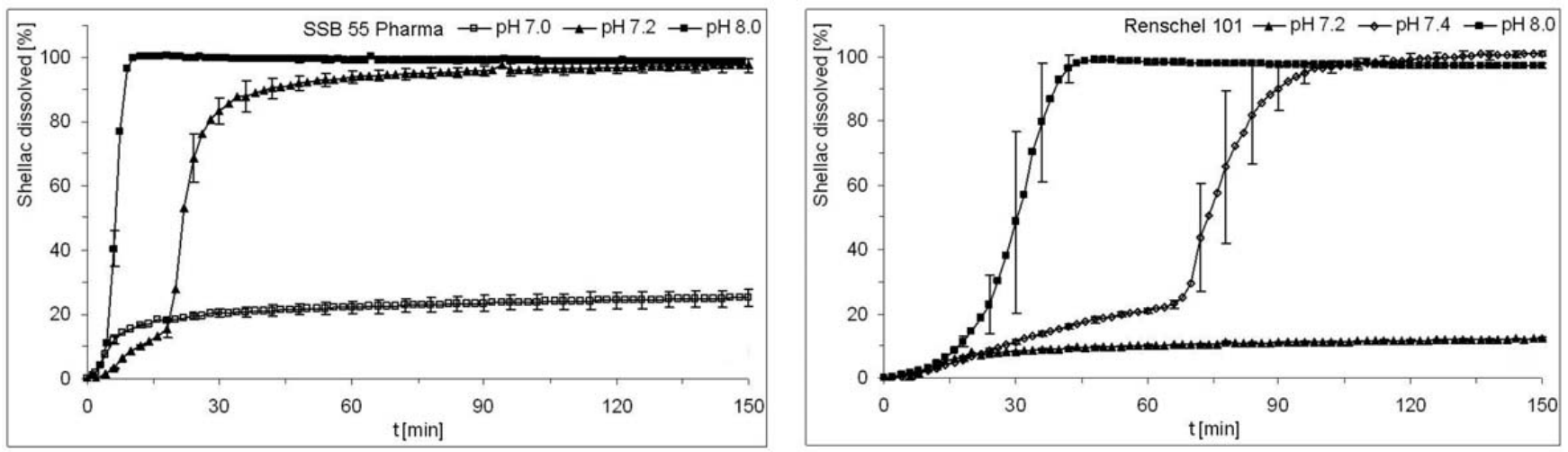

(C)

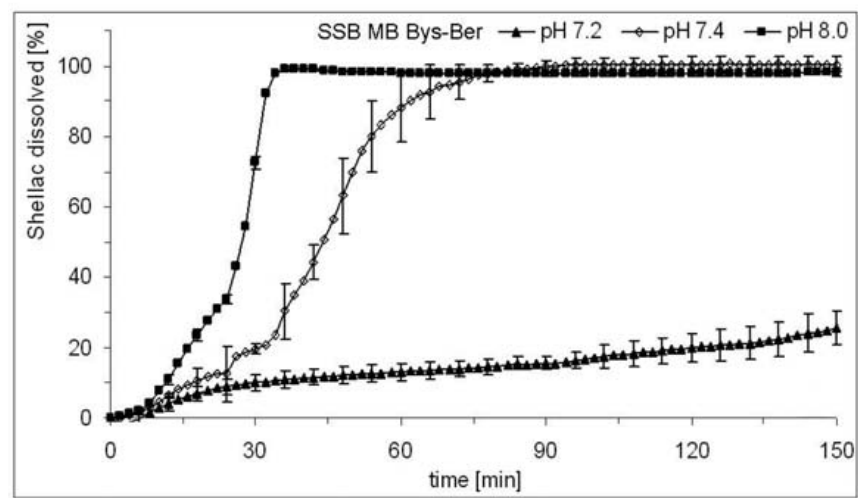

(F)

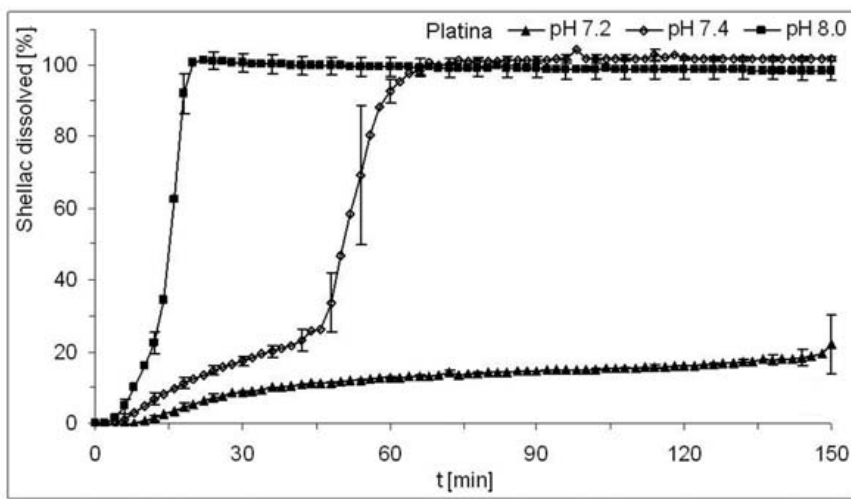

Figure 5. Dissolution profiles of the investigated shellac types at various pH values. (A) SSB 56 Pharma and SSB 57 Pharma, (B) SSB 55 Pharma (batch 109620), (C) SSB MB Bys Ber, (D) SSB MB Bes Pal, (E) Shellac 101, (F) Platina (mean \pm SD, $n=3$ ).

surface area to the dissolution medium. The ID rate follows a zero-order kinetic if sink conditions are maintained, and it only depends on the intrinsic properties of the material. The ID rate represents an appropriate material constant for the characterization of the different shellac batches.

ID experiments were performed for the batches of SSB 55 Pharma, SSB 56 Pharma, and Platina shellac. Based on the results of the dissolution experiments with the shellac film samples, the $\mathrm{pH}$ values for the ID experiments were chosen to be between 7.4 and 8.0 . In preliminary experiments, a compaction force of $200 \mathrm{~kg}$ held for 2 min was chosen for compression in a 9-mm die. Lower forces led to insufficient compaction and a disruption of the sample during the dissolution experiment. Much higher compaction forces resulted in changes of the sample morphology, manifesting themselves in altered dissolution properties. 


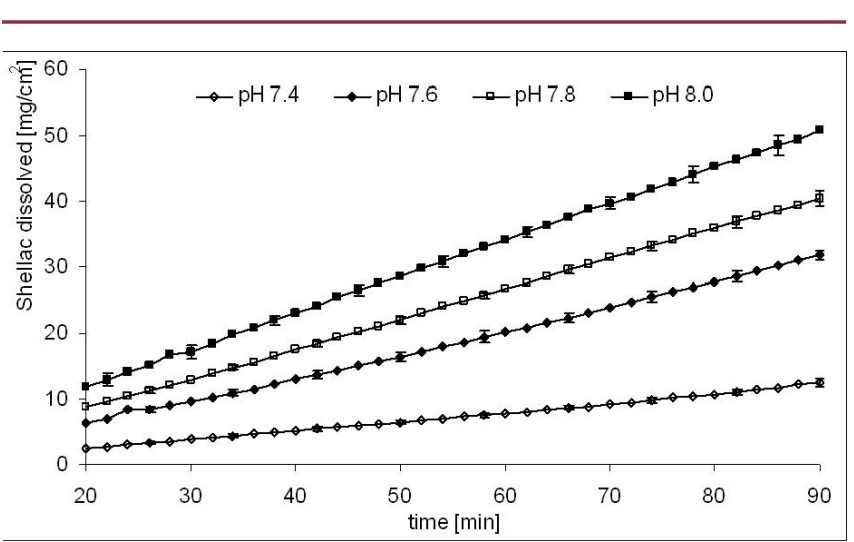

Figure 6. Intrinsic dissolution profiles of SSB 55 Pharma at various $p H$ values (mean $\pm S D, n=3 ; R^{2}$ between 0.9999 and 0.9997).

Figure 6 shows the ID profile for batch 109620 of SSB 55 Pharma. For all samples, ID profiles with a linear shape and good reproducibility were obtained. The ID rate of SSB 56 Pharma could not be measured with these experimental parameters and is therefore not shown. Because of the poor solubility of the material, sink conditions could not be maintained during the experiment. Therefore, the ID profiles are not linear and the ID rate cannot be determined.

As in the dissolution experiments with the shellac films, a pH dependence of the ID rate was observed (Figure 7). The ID rate increased at higher $\mathrm{pH}$ values. At $\mathrm{pH} 7.4$, the ID rates for all investigated batches of SSB 55 Pharma are equal. This is because this $\mathrm{pH}$ is close to the dissolution limit of shellac. Compared with the younger batches, the $\mathrm{pH}$ dependency of the ID rate is less pronounced with the oldest batch. With batches 106920 and 110580 of SSB 55 Pharma, the ID rate-pH profiles do not differ significantly. The ID rate more than doubles if the $\mathrm{pH}$ value is increased from 7.4 to 7.6. At higher $\mathrm{pH}$ values, the ID rate does not

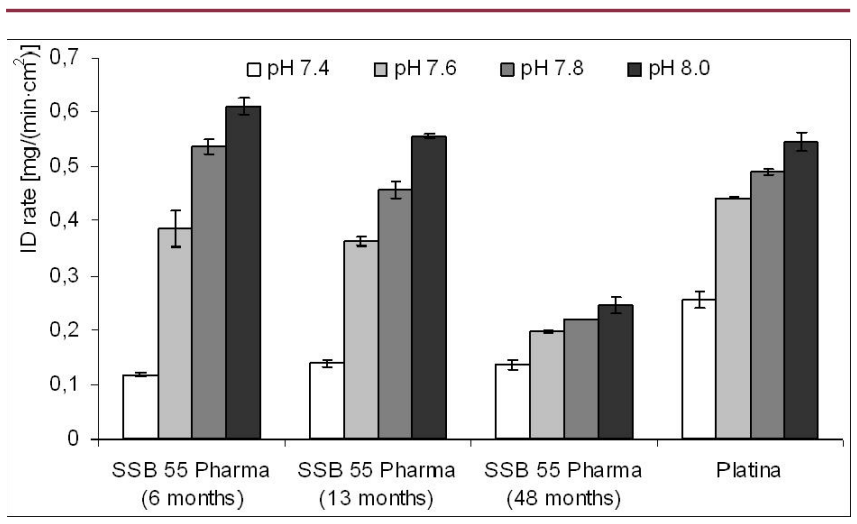

Figure 7. Intrinsic dissolution-pH profiles of the investigated shellac types (mean $\pm S D, n=3$ ). increase to the same extent. However, there seems to be no linear relationship between the ID rate and the $\mathrm{pH}$ value. The similarity of the ID rate versus $\mathrm{pH}$ profiles of the two batches indicates that polymerization does not affect the solubility during the first year of storage for this shellac type. However, after longer storage periods, the ID rate versus $\mathrm{pH}$ profiles are significantly changed.

For Platina shellac, the ID rate at $\mathrm{pH} 7.4$ was determined to be about twice that of the other batches at the same $\mathrm{pH}$ value. In contrast, at higher $\mathrm{pH}$ values, the ID increase was not as pronounced as for the younger batches of SSB 55 Pharma. Therefore, intrinsic dissolution is a suitable tool for the detection of polymerized shellac as well as for the distinction of different shellac types.

The $\mathrm{p} K_{a}$ value describes the acid strength and therefore the material's ability to dissociate. The $\mathrm{p} K_{a}$ values of the different shellac types vary between 5.8 and 6.1 (Table 1). These values do not correspond to the higher (about $1 \mathrm{pH}$ unit) values found in the literature $(13,15,16)$, while for Eudragit $L$ and acetic acid, the published values are confirmed. A possible explanation for this discrepancy is the different source of the investigated shellac types. While the shellac types in this study are of Indian origin, most of the shellac types described in the literature are Thai shellacs obtained by a melting filtration process and contain wax.

The $\mathrm{p} K_{a}$ range of about 0.3 units does not explain the differences in the dissolution behavior of the investigated shellac types, particularly not the almost complete insolubility of SSB 56 Pharma in the tested media.

Polymerization of shellac results in a loss of solubility while the $\mathrm{p} K_{a}$ value remains unchanged. Therefore, the determination of the $\mathrm{p} K_{a}$ value is unsuitable as a tool for the quality control of a single shellac type.

\section{CONCLUSION}

Even though the investigated shellac types met the pharmacopoeial specifications for physicochemical properties such as $\mathrm{AV}, T_{g}$, and $\mathrm{p} K_{a}$ value, dissolution profiles

Table 1.pK Values of the Investigated Shellac Types $(n=5)$

\begin{tabular}{lcc}
\hline Shellac Type & Batch & $\begin{array}{c}\mathbf{p} \boldsymbol{K}_{a} \text { value } \\
\text { (mean } \pm \text { SD) }\end{array}$ \\
\hline SSB 55 Pharma & 109620 & $5.85 \pm 0.02$ \\
\hline SSB 56 Pharma & 7249 & $6.01 \pm 0.02$ \\
\hline SSB 57 Pharma & 7176 & $6.01 \pm 0.01$ \\
\hline SSB MB Bys-Ber & $2918 \mathrm{~A}$ & $6.08 \pm 0.04$ \\
\hline SSB MB Bys Pal & $2918 \mathrm{~B}$ & $6.12 \pm 0.02$ \\
\hline Shellac 101 & 564 & $6.05 \pm 0.01$ \\
\hline Platina & SSF-134-2004-05 & $5.94 \pm 0.01$ \\
\hline
\end{tabular}


varied in a wide range. This is partly due to the different sources of the substance (insect species, host tree) and the refining process, but is mostly a result of the aging process. Dissolution experiments are a suitable tool to characterize shellac. The intrinsic dissolution is an appropriate method for the characterization of the dissolution properties of shellac and therefore a useful tool for quality assurance of shellac-containing drug formulations.

Shellac raw material is provided in its acid form, which is subject to an unpredictable change in the chemical structure. For long-term storage of the substance, the use of ammoniacal solutions or solid ammonium shellac is recommended.

\section{ACKNOWLEDGMENTS}

The authors would like to thank Syntapharm GmbH (Manfred Penning) for providing free shellac samples.

\section{REFERENCES}

1. Cockeram,H.S.; Levine, S. A. The physical and chemical properties of shellac. J. Soc. Cosmet. Chem. 1961, 12, 316-323.

2. Chauhan, V. S.; Sri Ram, N.; Subramanian, G. B.V.; Singh, $\mathrm{H}$. Chromatographic separation of the alkaline hydrolysis products of shellac. J. Chromatogr. 1973, 84 (1), 51-58.

3. Penning, M. Schellack—ein "nachwachsender" Rohstoff mit interessanten Eigenschaften und Anwendungen. Seifen Öle Fette Wachse 1990, 6, 221-224.

4. Kanokpongpaiboon, A.; Luangtana-Anan, M.; Nunthanid, J.; Limmatvapirat, C.; Puttipipatkhachorn, S.; Limmatvapirat, S. Investigation of shellac as a material for sustained drug release. In Proceedings of the 2nd AASP Symposium \& 2nd ApEM Conference, Bangkok, Thailand, 2005; pp 173-175.

5. Roda, A.; Simoni, P.; Magliulo, M.; Nanni, P.; Baraldini, M.; Roda, G.; Roda, E. A new oral formulation for the release of sodium butyrate in the ileo-cecal region and colon. World J. Gastroentero. 2007, 13, 1079-1084.

6. Sheorey, D. S.; Shastri, A. S.; Dorle, A. K. Effect of variables on the preparation of shellac microcapsules by solvent evaporation technique: Part 1.Int. J. Pharm. 1991, 68, 19-23.

7. Okamoto, M. Y.; Ibanez, P. S. Final Report on the safety assesment of shellac. J. Am. Coll. Toxicol. 1986, 5, 309-327.

8. Hagenmaier, R. D.; Shaw, P.E. Permeability of Shellac Coatings to Gases and Water-Vapor. J. Agric. Food Chem. 1991, 39, 825-829.

9. Pearnchob, N.; Siepmann, J.; Bodmeier, R. Pharmaceutical applications of shellac: Moistureprotective and taste-masking coatings and extendedrelease matrix tablets. Drug Dev. Ind. Pharm. 2003, 29, 925-938.

10. Specht, F. M.; Saugestad, M.; Waaler, T.; Müller, B.W.The application of shellac as an acidic polymer for enteric coating. Pharm. Technol. Eur. 1998, 10, 20-28.

11. Müller, B.W.; Yunis-Specht, F. Ammonium shellac-A new formulation of shellac for the application of a formerly used natural polymer for enteric coatings. In: Proceedings of the 21st International Symposium on Controlled Release of Bioactive Materials, Deerfield, II, USA, 1994; pp 760-761.

12. Parke, T.V.; Davis, W.W. Use of Apparent Dissociation Constants in Qualitative Organic Analysis. Anal. Chem. 1954, 26, 642-645.

13. Limmatvapirat, S.; Limmatvapirat, C.; Luangtana-Anan, M.; Nunthanid, J.; Oguchi, T.; Tozuka, Y.; Yamamoto, K.; Puttipipatkhachorn, S. Modification of physicochemical and mechanical properties of shellac by partial hydrolysis. Int. J. Pharm. 2004, 278, 41-49.

14. Limmatvapirat, S.; Limmatvapirat, C.; Puttipipatkhachorn, S.; Nuntanid, J.; Luandana-Anan, M. Enhanced enteric properties and stability of shellac films through composite salts formation. Eur. J. Pharm. Biopharm. 2007, 67, 690-698.

15. Pearnchob, N.; Dashevsky, A.; Bodmeier, R. Improvement in the disintegration of shellac-coated soft gelatin capsules in simulated intestinal fluid. J. Controlled Release 2004, 94, 313-321.

16. Luangtana-anan, M.; Limmatvapirat, S.; Nunthanid, J.; Wanawongthai, C. Effect of salts and plasticizers on stability of shellac film. J. Agric. Food Chem. 2007, 55, 687-692. 